\title{
Negative Correlation between Urinary Selenium and Arsenic Levels of the Residents Living in an Arsenic-Contaminated Area in Bangladesh
}

\author{
Kaori Miyazaki, ${ }^{*, a}$ Kayo Ushijima, ${ }^{b}$ Takefumi Kadono, ${ }^{c}$ Tsukasa Inaoka, ${ }^{d}$ Chiho Watanabe, ${ }^{a}$ \\ and Ryutaro Ohtsuka ${ }^{a}$
}

${ }^{a}$ Department of Human Ecology, School of International Health, Graduate School of Medicine, University of Tokyo, 7-3-1, Hongo, Bunkyo-ku, Tokyo 113-0033, Japan, ${ }^{b}$ Department of Public Health, School of Medicine, Fukuoka University, 7-45-1, Nanakuma, Jyonan-ku, Fukuoka 814-0180, Japan, 'Department of Dermatology, University of Tokyo, 7-3-1, Hongo, Bunkyo-ku, Tokyo 113-0033, Japan, and ${ }^{d}$ Department of Environmental Sociology, Faculty of Agriculture, Saga University, 1 Honjo-machi, Saga 840-8502, Japan

(Received March 7, 2003; Accepted March 17, 2003)

Toxicological and metabolic interactions of selenium (Se) with arsenic (As) have been reported in many experimental studies. However, for human populations, possible interactions between As and Se and their toxicological significance have not been established. In this study, we have examined the relationship between Se and As in spot urine samples collected from the inhabitants of two rural communities of northeast Bangladesh. The urinary $\mathrm{As}\left(\mathrm{U}_{\mathrm{As}}\right)$ and $\mathrm{Se}\left(\mathrm{U}_{\mathrm{Se}}\right)$ concentrations were determined by hydride generation atomic absorption spectrometry (HGAAS). Negative correlation between $U_{A s}$ and $U_{S e}$ was found in both males and females. Considering the exposure condition in these communities, it is unlikely that the correlation reflected the correlation between the intakes of these elements. This result suggests that As exposure from drinking water or food may change Se metabolism in humans. Possible toxicological significance of the interaction is discussed.

Key words — arsenic, selenium, interaction, Bangladesh

\section{INTRODUCTION}

The effects on human health of arsenic (As) exposure from drinking tubewell water of geologic origin are a major public health problem in many countries, including Bangladesh, India, China, Chile, Argentina, and Peru. This hazard is particularly se-

*To whom correspondence should be addressed: Department of Human Ecology, School of International Health, Graduate School of Medicine, University of Tokyo, 7-3-1, Hongo, Bunkyo-ku, Tokyo 113-0033, Japan. Tel.: +81-3-5841-3529; Fax: +81-3-5841-3395; E-mail: kaori@humeco.m.u-tokyo.ac.jp rious in Bangladesh, where 35 to 77 million of the 125 million inhabitants are estimated to be at risk. ${ }^{1)}$ Chronic exposure to As causes dermatological, cardiovascular, neurological, and neurodevelopmental disorders, and cancers. ${ }^{2,3)}$

Selenium (Se) is an essential microelement that negates the toxic effects of several heavy metals, ${ }^{4}$ and its toxicological and metabolic interactions with As have been reported in many animal experiments. Moxon and Du Bois ${ }^{5)}$ revealed the protective effects of As against liver damage and growth depression, both of which are caused by excessive consumption of seleniferous grain, though the mechanisms of protection by Se against As toxicity have not yet been clarified. The experiments of rats injected with ${ }^{75} \mathrm{Se}$ and As have demonstrated that increase in the As dose markedly increased the amount of ${ }^{75} \mathrm{Se}$ in the excreted bile, and the increased amount of ${ }^{75} \mathrm{Se}$ was approximately equivalent to the decreased amount of ${ }^{75} \mathrm{Se}$ in the liver. ${ }^{6,7)}$ Keyon et al.$^{8)}$ have reported that mice fed Se-deficient diet eliminated arsenate, arsenite and dimethylarsinic acid (DMA) in urine more slowly than those fed Se-suficient diet.

For human populations, very few such studies have been carried out. Lin and Yang ${ }^{9)}$ reported that black foot disease (BFD) patients in Taiwan had lower blood and hair Se concentrations than normal controls. Wang ${ }^{10)}$ indicated that urinary Se $\left(\mathrm{U}_{\mathrm{Se}}\right)$ concentrations were significantly lower in BFD patients than in healthy controls. Wuyi et al. ${ }^{11)}$ found a decrease in the hair, urinary, and blood As concentrations, together with marked improvement in the skin manifestations, in patients supplemented with Se (100-200 $\mu \mathrm{g}$ Se/day) versus those receiving a placebo in a 14-month study of arsenism patients. The toxicological significance of Se and its possible in- 
teractions with As have not been established in human pupulations. It is possible that As could disturb normal metabolism of Se in human populations. This study examined the relationship between $\mathrm{As}$ and $\mathrm{Se}$ levels in urine in two Bangladeshi communities with known As contamination. ${ }^{12)}$

\section{MATERIALS AND METHODS}

\section{Study Populations and Sample Collection -} The communities, (SV and SP), located in Sibganj thana, Nawabganj district, northwestern Bangladesh were the subject areas in this study. Their water supply is entirely dependent on about 100 tubewells in the two villages, some of which were installed by individual households while others were installed by the government for common use among several households. Spot urine samples were collected from 170 males and 259 females aged 12 years or more in February and March 1999, along with the collection of all tubewell water. ${ }^{12)}$ The participation of the inhabitants was voluntary. The collected urine samples were kept in a freezer and transported to Japan, where they were kept at $-80^{\circ} \mathrm{C}$ until element determination. All the procedures were approved by the Ethics Committee of the Graduate School of Medicine of the University of Tokyo, and written informed consent was obtained from each participant.

Urinary As and Se Determination — The total As concentration in the urine samples was determined using an atomic absorption spectrometer equipped with a flow-injection hydride generator [hydride generation atomic absorption spectrometry (HGAAS); ZL-4100, Perkin Elmer, U.S.A.] after wet-ashing the samples with a mixture of $\mathrm{HNO}_{3}$, $\mathrm{HClO}_{4}$, and $\mathrm{H}_{2} \mathrm{SO}_{4}{ }^{12)}$ To determine Se concentration, the urine samples were wet-ashed by heating with a mixture of $\mathrm{HNO}_{3}$ and $\mathrm{HClO}_{4}$, and Se was determined with the HGAAS after prereduction with $\mathrm{HCl}$. The detection limits of As and Se were 3 and $1 \mu \mathrm{g} / \mathrm{l}$, respectively.

The accuracy of the As and Se assays was ensured by including reference material (NIES\#18 "human urine," National Institute of Environmental Studies, Tsukuba, Japan). The values obtained for both elements fell within the certified ranges $(0.137 \pm 0.011$ for As and $0.059 \pm 0.005 \mathrm{mg} / \mathrm{l}$ for Se). The creatinine (Cre) concentration was spectrophotometrically determined using a commercial kit (Creatinine Wako, Wako Pure Pharmaceuticals,
Table 1. Urinary Arsenic and Selenium Concentration by Sex and by Village

\begin{tabular}{|c|c|c|}
\hline village and sex & $\mathrm{U}_{\mathrm{As}}[\mu \mathrm{g} / \mathrm{g} \mathrm{Cre}]$ & $\mathrm{U}_{\mathrm{Se}}[\mu \mathrm{g} / \mathrm{g}$ Cre $]$ \\
\hline \multicolumn{3}{|l|}{$\mathrm{SP}$} \\
\hline male $(n=79)$ & $\begin{array}{c}131.8 \pm 2.3 \\
\left.(32-1822)^{a}\right)\end{array}$ & $\begin{array}{c}23.4 \pm 1.5 \\
(4-71)\end{array}$ \\
\hline female $(n=137)$ & $\begin{array}{c}166.0 \pm 2.5 \\
(24-2017)\end{array}$ & $\begin{array}{c}23.3 \pm 1.6 \\
(4-63)\end{array}$ \\
\hline \multicolumn{3}{|l|}{ SV } \\
\hline male $(n=90)$ & $\begin{array}{c}208.9 \pm 1.9 \\
(62-1257)\end{array}$ & $\begin{array}{c}17.4 \pm 1.6 \\
(4-48)\end{array}$ \\
\hline female $(n=119)$ & $\begin{array}{c}218.8 \pm 2.4 \\
(42-1653)\end{array}$ & $\begin{array}{c}16.2 \pm 1.8 \\
(2-44)\end{array}$ \\
\hline \multicolumn{3}{|l|}{$\mathrm{ANOVA}^{b)}$} \\
\hline village & $p<0.001$ & $p<0.001$ \\
\hline sex & $0.05<p<0.1$ & NS \\
\hline village $\mathrm{x}$ sex & NS & NS \\
\hline
\end{tabular}

Note: Geometric mean and SD are shown. a) The ranges of $\mathrm{U}_{\mathrm{As}}$ and $\mathrm{U}_{\mathrm{Se}}$ are indicated in parentheses. $b$ ) Two-way ANOVA using log-transformed variables. NS, not significant $(p>0.1)$.

Osaka, Japan), based on Jaffe's reaction. ${ }^{13)}$

Statistical Analysis — Each individual's $\mathrm{U}_{\mathrm{Se}}$ and urinary As $\left(\mathrm{U}_{\mathrm{As}}\right)$ concentrations were logarithmtransformed to ensure normality in distribution. Between-group differences in the transformed data were tested by analysis of variance (ANOVA), using the JMP software program (version 4.0; SAS Institute, Cary, NC, U.S.A.). The reported correlation coefficient $r$ is the Pearson correlation coefficient. The probability level was set at $p<0.05$.

\section{RESULTS}

\section{$\mathbf{U}_{\mathrm{As}}$ and $\mathbf{U}_{\mathrm{Se}}$ Concentrations}

The $\mathrm{U}_{\mathrm{As}}$ and $\mathrm{U}_{\mathrm{Se}}$ concentrations varied considerably among the subjects. The mean was significantly higher in SV than those in SP for both sexes, while the mean $\mathrm{U}_{\mathrm{Se}}$ was significantly higher in SP than in $\mathrm{SV}$ for both sexes (Table 1). With respect to sex differences, $\mathrm{U}_{\mathrm{As}}$ was higher in females than in males when the two village groups were analyzed separately or together (Table 1 ).

\section{Relation between $\mathrm{U}_{\mathrm{As}}$ and $\mathrm{U}_{\mathrm{Se}}$}

When the data from the two communities were pooled, $\mathrm{U}_{\mathrm{As}}$ was negatively correlated with $\mathrm{U}_{\mathrm{Se}}$ in both females $(r=-0.25, p<0.01)$ and males $(r=-0.16, p<0.05)$, although a significant correlation was found only in SV females $(r=-0.29$, $p<0.01$; data not shown) when the two communi- 

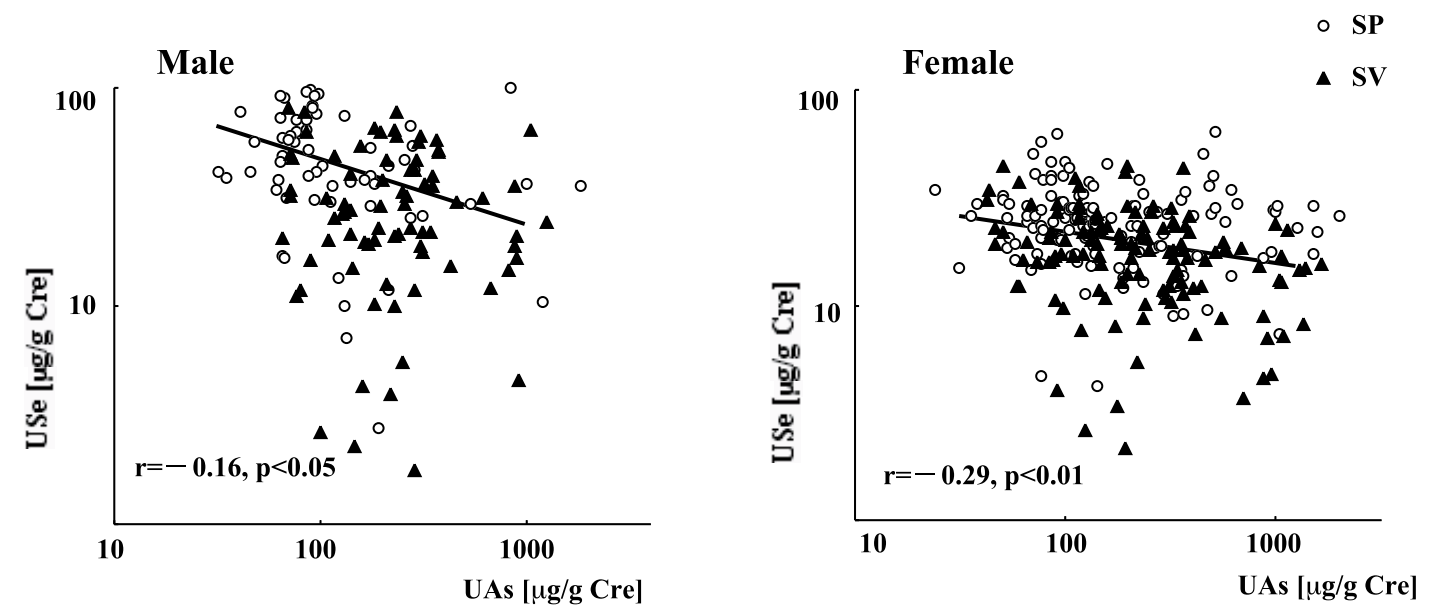

Fig. 1. Relationship between $U_{A s}$ and $U_{S e}$ in Males (Left) and in Females (Right)

Each dot denotes one individual; open circles $=\mathrm{SP}$, closed triangles $=\mathrm{SV}$. The lines are the regression lines for each sex with the Pearson's correlation coefficient between $\log \mathrm{U}_{\mathrm{As}}$ and $\log \mathrm{U}_{\mathrm{Se}}$.

ties were analyzed separately (Fig. 1).

\section{DISCUSSION}

The results of this study highlight the inverse correlation between $\mathrm{U}_{\mathrm{As}}$ and $\mathrm{U}_{\mathrm{Se}}$ in both females and males in the combined populations of the two villages. It should be note that we have observed with a high-performance liquid chromatography-inductively coupled plasma mass spectrometry (HPLCICP-MS) assay that the urine samples of this population contained only inorganic arsenic and its methylated metabolites [monomethylarsonic acid (MMA) and DMA] but no other chemical species such as arsenobetaine were detected. Hsueh et al. ${ }^{14)}$ recently showed that $\mathrm{U}_{\mathrm{As}}$ increased with $\mathrm{U}_{\mathrm{Se}}$ among healthy residents of As-affected area (Lanyang Basin) in Taiwan, differing from the observation in this study. The reason for the discrepancy among these observations has not been elucidated, but it might be due to the difference in the levels of As exposure, since the $\mathrm{U}_{\mathrm{As}}$ concentrations of our subjects (Table 1; note that the arithmetic mean of the $\mathrm{U}_{\mathrm{As}}$ in our subjects were $281 \mu \mathrm{g} / \mathrm{g}$ Cre) were higher than those in Hsueh's study (arithmetic mean, $96.9 \pm 7.3 \mu \mathrm{g} / \mathrm{l}$ ).

The considerable overlap of the ranges of $U_{A s}$ and $U_{\mathrm{Se}}$ of the two villages suggests that the inverse correlation was not merely resulting from the between-village differences in these variables. There are several ways to explain this inverse correlation, which will be discussed hereafter.

First, since the urinary excretions of both Se and
As are known to reflect the intakes of each element, the inverse correlation might reflect the inverse correlation between the intakes of these two elements. It is known that the major source of As in this area is tube-well water, whose As concentrations vary from less than 1 to more than $500 \mu \mathrm{g} / \mathrm{l}$. In fact, in the present subjects, a highly positive correlation was obtained between As concentration in the tube-well water $\left(\mathrm{TW}_{\mathrm{As}}\right)$ used by an individual and his/her $\mathrm{U}_{\mathrm{As}}$. Thus, if the inverse correlation reflected the correlation between the intakes of $\mathrm{As}$ and $\mathrm{Se}$, it must be assumed those who had high $\mathrm{TW}_{\mathrm{As}}$ has lower intake of Se, which should be mainly derived from food. Since $\mathrm{TW}_{\mathrm{As}}$ is randomly distributed among the subjects, existence of such relationship is unlikely.

Alternatively, the inverse correlation might be indicative of metabolic interaction between these two elements. Although human evidence is scarce, several animal studies showed that such metabolic interactions do exist. In rats, dietary exposure to As significantly enhanced the fecal excretion of Se, with a concomitant decrease in urinary excretion of Se. ${ }^{15}$ ) In rats increasing As dose markedly increased the biliary excretion of co-administered ${ }^{75} \mathrm{Se}$, and the increase was approximately equivalent to the decrease of ${ }^{75} \mathrm{Se}$ in the liver. ${ }^{6,7)}$ Using mice, we have also observed that repeated administration of subtoxic dose of As decreased hepatic Se concentration (unpublished data). Although the precise mechanisms are not clear, these observations suggests that As exposure changes Se metabolism, enhancing the excretion of Se via bile or feces, thereby leading to decreased urinary Se excretion. Overall, 
these experimental observations are in line with the present result in human. In this connection, it is plausible that the between-village difference in As exposure (due to the between-village difference in $\mathrm{TW}_{\mathrm{As}}$ ) led to the between-village difference in $\mathrm{U}_{\mathrm{Se}}$ in the study populations.

In conclusion, this study showed negative correlation between $U_{A s}$ and $U_{S e}$ in both males and females of two As-affected rural communities in northwestern Bangladesh, suggesting that As exposure from drinking water or food may change the metabolism of Se in human population. Such disturbance of normal Se metabolism per se may lead to several adverse effects; e.g., impairment of antioxidant selenoenzymes (glutathione peroxidase and thioredoxin reductase). In addition, considering that thioredoxin reductase is a sensitive target of As, ${ }^{16)}$ the interaction may also potentiate the toxicity of As. In this respect, the relationships between nutritional status regarding $\mathrm{Se}$ and the markers of Asinduced oxidative stress or diseases (cancer, skin manifestation etc.) needed to be examined in future epidemiological studies.

Acknowledgements This study was financially supported by the Alliance for Global Sustainability and the Japanese Ministry of Education, Culture, Sports, Science, and Technology (Project Nos.: 10044240 and 12470082). We thank all the subject villagers who participated in this study and the local health officers and assistants for their generous and enduring help and collaboration. We are also indebted to Mr. M. H. Bokul, Dr. A. Ahmad, and Dr. E. Karim for providing continuous support and valuable advice for our survey.

\section{REFERENCES}

1) Smith, A. H., Lingas, E.O. and Rahman, M. (2000) Contamination of drinking-water by arsenic in Bangladesh: a public health emergency. Bull. World Health Organ., 78, 1093-1103.

2) Chen, C. J., Chuang, Y. C., Lin, T. M. and Wu, H. Y. (1985) Malignant neoplasms among residents of a Blackfoot disease endemic area in Taiwan: higharsenic artesian well water and cancers. Cancer Res., 45, 5895-5899.

3) Smith, A. H., Goycolea, M., Haque, R. and Biggs, M. L. (1998) Marked increase in bladder and lung cancer mortality in a region of northern Chile due to arsenic in water. Am. J. Epidemiol., 147, 660-669.
4) Levander, O. A. (1977) Metabolic interrelationships between arsenic and selenium. Environ. Health Perspect., 19, 159-164.

5) Moxon, A. L. and Du Bois, K. P. (1939) The influence of arsenic and certain other elements on the toxicity of seleniferous grains. J. Nutr., 18, 447457.

6) Ganther, H. E. and Baumann, C. A. (1962) Selenium metabolism. I. Effects of diet, arsenic, and cadmium. J. Nutr., 77, 210-216.

7) Levander, O. A. and Baumann, C. A. (1966) Selenium metabolism VI. Effects of arsenic on the excretion of selenium in the bile. Toxicol. Appl. Pharmacol., 9, 106-115.

8) Kenyon, E. M. and Hughes, M. F. (1997) Influence of dietary selenium on the disposition of arsenate in the female B6C3F1 mouse. J. Toxicol. Environ. Health, 51, 279-299.

9) Lin, S. M. and Yang, M. H. (1988) Arsenic, selenium, and zinc in patients with blackfoot disease. Biol. Trace Elem. Res., 15, 213-221.

10) Wang, C. T. (1996) Concentration of arsenic, selenium, zinc, iron, and copper in the urine of blackfoot disease patients at different clinical stages. Eur. J. Clin. Chem. Clin. Biochem., 34, 493-497.

11) Wuyi, W., Linsheng, Y., Shaofan, H., Jian'an, T. and Hairong, L. (2001) Prevention of endemic arsenism with selenium. Curr. Sci., 81, 1215-1218.

12) Watanabe, C., Inaoka, T., Kadono, T., Nagano, M., Nakamura, S., Ushijima, K., Murayama, N., Miyazaki, K. and Ohtsuka, R. (2001) Males in rural Bangladeshi communities are more susceptible to chronic arsenic poisoning than females: Analyses based on urinary arsenic. Environ. Health Perspect., 109, 1265-1270.

13) Bonsnes, R. and Taussky, H. (1945) On the colorimetric determination of creatinine by Jaffe reaction. J. Biol. Chem., 158, 581.

14) Hsueh, Y. M., Ko, Y. F., Huang, Y. K., Chen, H. W., Chiou, H. Y., Huang, Y. L., Yang, M. H. and Chen, C. J. (2003) Determinants of inorganic arsenic methylation capability among residents of the Lanyang Basin, Taiwan: arsenic and selenium exposure and alcohol consumption. Toxicol. Lett., 137, 49-63.

15) Pederson, N. D., Butler, J. A. and Whanger, P. D. (1991) Influence of arsenic on selenium metabolism and glutathione peroxidase activity in rats. J. Trace Elem. Electrolytes Health Dis., 5, 75-80.

16) Lin, S., Del Razo, L., Styblo, M., Wang, C., Cullen, W. R. and Thomas, D. J. (2001) Arsenicals inhibit thioredoxin reductase in cultured rat hepatocytes. Chem. Res. Toxicol., 14, 305-311. 